an angle of $2^{\circ}$ had been used at $24^{\circ} \mathrm{C}$. and the lower platen modified so that the sample could be surrounded by an annulus of solution to keep it at constant humidity. It had been found that rotation experiments could not be conducted as the dough immediately rolled out of the gap. Using oscillation experiments the effect of relaxation between the plates had been studied. The doughs $(56 \cdot 0$ per cent absorption, 2.5 per cent sodium chloride) had been mixed on a farinograph under constant conditions and allowed to relax between the platens from 15 sec. to $120 \mathrm{~min}$. They were tested at 6 cycles $/ \mathrm{min}$. and an amplitude of $1^{\circ} 15^{\prime}$. This was the largest amplitude at which no normal pressure was discernible. Elastic modulus and coefficient of viscosity, both of the order of $10^{4}$ c.g.s., dropped during 120 -min. relaxation from $6.5 \times 10^{4}$ to $1.5 \times 10^{4}$ c.g.s., the largest reduction occurring during the first $45 \mathrm{~min}$. When the frequency was altered from 4 to 15 cycles/ min. at a relaxation time of $60 \mathrm{~min}$., the modulus remained unchanged while the coefficient of viscosity decreased from $3.5 \times 10^{4}$ to $1.5 \times 10^{4}$ c.g.s. At 15 cycles/min. vibrations were observed in the instrument. It was proposed that exchangeable cone and plate assemblies should be designed for substances requiring longer relaxation times.

In reply, Mr. King pointed out that certain plastics showed cavitation during tests, but as yet no other material had rolled up making rotation experiments impossible. Exchangeable assemblies had been considered, but technical difficulties had so far prevented a solution. He also suggested that perhaps dough should be regarded as a readily deformable solid, and testing programmes be formulated accordingly, as this material does not exhibit viscous behaviour during rotational tests with a cone and plate.

On the day following the meeting, samples of human blood plasma, provided by Drs. D'A. Kok and J. Mehrishi (University of Cambridge), and bovine synovial fluid, submitted by Dr. J. Harris (Orthopædic Hospital, Stanmore), were tested. With the former no readings could be obtained. Using a $1^{\circ}$ cone of $7.5 \mathrm{~cm}$. diameter at $30^{\circ} \mathrm{C}$. and a shear-rate of 360 sec. $^{-1}$ with the latter, no normal force was observed. The viscosity was 0.0104 poises. At $9 \cdot 04,57$ and 180 sec. $^{-1}$ and a $2^{\circ}$ cone no stress readings could be obtained. The fluid broke down rapidly during the test. A drop of it spilt during the experiment immediately corroded the cast-iron base of the instrument.

The next meeting of the club will be held on October 29 at the Technological Research Station, Spillers, Ltd., Station Road, Cambridge, when Mr. J. F. Hutton (Shell Research, Ltd.) will speak on "The Rheology of Motor Oils". H. G. MULLER

\title{
STANDARDS IN SCIENTIFIC PUBLICATION
}

\section{$\mathrm{T}$} HE Scientific Publications Council met at University College, London, on May 31, to discuss "What is a High Standard of Scientific Publication and how is it Attained?". Prof. G. W. Harris (Maudsley Hospital, London) took the chair.

Prof. W. V. Thorpe (Department of Physiology, Birmingham) introduced the subject. As editor-inchief of the Biochemical Journal, he confined his remarks to periodicals publishing original scientific work, as opposed to reviews or monographs. High standards in such journals imply publishing clear and accurate accounts of original contributions to research on which others can build. How is this achieved?

First, Prof. Thorpe suggested the editorial board must refrain from selecting topical and interesting papers in preference to unexciting routine work, for what is dull to a man working in one field, may be of vital importance to those working in others. The editors must guard against rejecting poorly written papers for that reason alone, since it is their duty to help inexperienced or foreign authors to describe their work in an acceptable style. Since science is an international endeavour, colloquialisms, jargon and abbreviations should be avoided and care taken that unfamiliar terms are explained so that the meaning may be clear to foreign readers unversed in the language of publication. For the same reason it is good practice to adopt, so far as possible, internationally agreed usage with regard to nomenclature and units, and a standard form should be used for references. The International Union of Biochemistry recently set up a Commission of Editors of Biochemical Journals to encourage international agreement on such matters.

Verbose and repetitive styles must be amended, since clarity and conciseness not only make the text more easily intelligible but also save readers' time and, incidentally, reduce the cost of publication. Experiments should be so described that they can be repeated without further research or correspondence with the authors. An author can assist in reducing the delay between submission and publication by preparing his contribution carefully so as to reduce editorial processing to a minimum and to eliminate any necessity for revising the manuscript.

Editors should be vigilant to the point of suspicion and should check all statements which are readily susceptible to testing, for example, that totals are correctly added and that theoretical values for elementary analyses are correctly calculated.

Ultimately the Editorial Board is the custodian of a journal's standards. That of the Biochemical Journal does not itself prepare papers for the pressthis is done by the editorial office staff-but exercises a judicial and very critical selection, communicates suggestions to authors on how to improve thoir manuscripts and, where necessary, explains why one has been rejected. Only 15 or 20 per cent of papers submitted have to be refused. Members of the Board are all active scientific workers and selected so as to provide collectively a balanced and critical judgment in many fields. Before a paper is accepted, it is normally submitted to the scrutiny of at least two members of the Board, one of whom is a specialist in the subject of the paper, while the other provides the point of view of the general scientific reader. If necessary an independent referee is consulted. High editorial morale is achieved by frequent discussion and self-criticism, including periodical scrutiny of the statistics of time-lag in publication so that causes of delay may be identified and so far as possible removed. 
Mr. A. L. Bacharach (British Journal of Nutrition, etc.) explained that the subject arose when the Council was framing the clause in its rules relating to its aims, namely, to promote and maintain high standards in the dissemination of scientific information and in particular of scientific books and journals. At that stage it seemed natural to try to define and prescribe for high standards in seientific publication. Mr. Bacharach declared his interest by pointing out that he had served on the editorial boards or publications committees of the Royal Institute of Chemistry and the Society for Chemical Industry, and of the Analyst, of the British Journal of Nutrition, Acta Pharmacologica et Toxicologica and others.

Whether the editorial policy of a journal is controlled by a learned society, by a commercial publish. ing house or, like the British Journal of Pharmacology, by a learned society and a publisher jointly, the aim should always be the same high standard.

Mr. Bacharach was in substantial agreement with Prof. Thorpe, but wished to extrapolate the argument a stage further. $\mathrm{He}$ thought that editorial boards should not over-stress the letter at the expense of the spirit by, for example, undue punctilio about conforming to internationally agreed conventions, for these are never so important as consistency and clarity.

The ultimate aim of editorial policy should be to foster a relationship of confidence between author and reader. For this it is of the first importance to establish a high level of scientific content. Papers should contain new information couched in an interesting style, free from ambiguity and expressed with clarity so that the work will be intelligible in theory and repeatable in practice.

Mr. Bacharach defined referees as all those specialists charged with judging the scientific value of a paper's contents, while editors he defined as those concerned with the form of a paper and its preparation for the press, and this irrespective of the way the terms may happen to be used by any particular publishing body. Often the same people may be involved, but their functions are distinct.

Some journals have recently been started with the special aim of securing rapid publication by the reproduction of authors' own typescripts using a photolithographic process. In this case the editors' function is reduced to a minimum, and the onus rests with the referees. The first requisite for critical standards of refereeing is that it should be possible to send a paper to any suitable specialist anywhere in the world, and at least two independent opinions should be obtained, at any rate before rejection. It is the duty of a referee to steer a careful course between the Scylla of academic orthodoxy and the Charybdis of extravagant novelty. The editor is concerned to secure a high standard of presentation in style and syntax and to eliminate all obscurity or illogicality, and he is fully entitled to take all necessary corrective action. Mr. Bacharach did not agree with those who hold that what an author writes is his own affair alone. To fail to obtain high standards of presentation is to abdicate from the editorial function and to connive at the reduction of a journal's status.

Mr. Bacharach then directed attention to the enormous proliferation of scientific publications in recent times and proposed a touchstone of justification for the appearance of a new journal. The rapid advances in science are continually blurring old boundaries and creating new disciplines. The test of a new journal is whether it will enable work lying across the boundaries of former traditional fields to come to the attention of workers on both sides of the division, whereas its publication in existing journals might bring it to the attention of one or the other only. The same criterion might be applied to the creation of new learned societies.

$\mathrm{Mr}$. Bacharach wondered what could be done about certain new journals, produced not under the ægis of learned societies but for commercial interests, relying for their circulation on what amounts to moral blackmail of librarians. Their publishers know that the mere existence of a work creates a demand for it, and their activities are detrimental to the interests of science in general, of libraries with limited space and funds, and of other more scrupulous publishers. A fortiori, the proliferation of technical books containing scientific information of an ephemeral or incomplete character represents a growing threat to the whole system of communication in science.

Finally, Mr. Bacharach remarked that Nature and similar journals exist for the rapid publication of short accounts of important new advances. The publication of most researches should wait until a complete account of the work is available. The insistence on speed in publication is a pathological development in science the influence of which is generally bad, being almost entirely at variance with the maintenance of high standards.

Dr. C. C. N. Vass (St. Thomas's Hospital Medical School, London) thought that the judicious selection of referees suitable for each manuscript submitted was one of the most important responsibilities of the editorial board and Mr. J. C. Graddon (assistant editor, Philosophical Transactions and Proceedings of the Royal Society) felt that anonymity of referees might be a decisive factor in securing impartial advice. Mr. P. C. Williams (Imperial Cancer Research Fund) pointed out that referees have different standards, and it was agreed that anyone whose standards were known to be too low-or too highshould not be consulted. Mr. Williams wondered whether zealous editing might not even afford some authors an unjustified reputation for exposition and, moreover, might encourage people to submit slipshod manuscripts. Mr. N. L. Harris (General Electric Co., Hirst Research Centre) thought that editorial changes should be confined to grammatical corrections and should not aim at creating a drab uniformity of style. However, Mr. Bacharach maintained that this was a bogy; editors in general have no time to edit style because they are all too frequently engaged in grappling with its absence.

Dr. C. A. Hogarth (Brunel College, Acton) asked what should be done with manuscripts betraying signs of having been rejected by other editors. Mr. Bacharach replied that some journals require a declaration that a paper has not been submitted elsewhere, but Dr. R. K. Callow (National Institute for Medical Research, Mill Hill) recalled the wellknown fact that Sir Hans Krebs's announcement of his work on the eitric acid cycle--for which he was later awarded the Nobel Prize-was refused by an eminent journal; there might be many reasons for the rejection by a particular journal of a paper without any reflexion on its scientific merits. It is then good editorial practice to refer an author to an alternative vehicle for publication. Mr. Graddon remarked that the Royal Society is frequently asked to accept papers which are too long and expensive for others 
to publish. It is a valuable custom that all manu. scripts have to be communicated through a Fellow of the Society, who should be able to criticize the presentation and act, to some extent, as referee before consenting to act as sponsor.

Mr. P. J. Edmonds (Publishers Association, Technical Group) applauded Prof. Thorpe's arrangements for periodic meetings of editors, production staff and printers; he thought that many of the problems with which the Council is concerned arise through imperfect comprehension between those responsible for the scientific, literary, technical and financial aspects of publication. Whilo appreciating $\mathrm{Mr}$. Bacharach's feelings about the proliferation of books and journals, he thought that the remedy lies with librarians and library committees, who should be more selective. Mrs. Olga Kennard (editor, Crystul Data) said that the publication of candidly critical reviews in reputable journals is the greatest safoguard, but Dr. A. J. Evans (librarian, School of Pharmacy, London) complained that even though economic considerations force librarians to be selective, reviews often appear too late to bo of much assistance to them.
A. V. S. DE REUCK

\section{THE FULMER RESEARCH INSTITUTE}

$\mathrm{A}^{\mathrm{N}}$ $\mathrm{N}$ open day was held at the Fulmer Research Institute on June 7. The occasion marked tho fiftcenth anniversary of the Institute's foundation and the completion of laboratory extensions.

The chairman, Mr. W. R. Merton, introduced the principal guest, Mr. Denzil Freeth, Parliamentary Secretary for Science, who emphasized in a short address that the Ministry did its best to persuade industry that scientific and technological rescarch is not only worth while, but is in fact economical and vital for progress, expansion and prosperity. The reply was often that it was too costly to set up extensive laboratories and engago specialized staff to carry out particular pieces of research. This was true, but it was to overcome this objection and to meet these needs that establishments where confidential sponsored research could be undertaken had been set up. Mr. Freeth eongratulated Fulmer on the high quality of its staff and specialized facilities and said that he envisaged a great future for sponsored rescarch.

The new extensions to the Physies and Physical Metallurgy Laboratories provide approximately 3,000 sq. ft. of additional laboratory space, about half of which is basement accommodation. Provision is made in the extensions to the Physical Metallurgy Laboratory for handling toxic materials, and in the oxtonsions to the Physics Laboratory for housing additional X-ray diffraction units, together with a new EM6 electron microscopc.

In recent yoars, a high proportion of the work of the Physies and Physical Metallurgy Sections has been concerned with metals of importanco in the field of nuclear power, such as uranium, zirconium and beryllium. In unalloyed uranium the orthorhombic $\alpha$-phase is stable up to $660^{\circ} \mathrm{C}$. and the anisotropic nature of the $\alpha$-phase can result in dimensional instability of fuel elements in the reactor. One way of avoiding this is by quenching dilute alloys from the $\beta$-phase region to give a fine-grained structure, free from preferred orientation. The mode and kineties of transformation of the $\beta$-phaso are being investigated at Fulmer using hot hardnoss, thermal analysis, X-ray diffraction and metallographic techniques; the structure of the $\beta$-phase is also being studied.

Another approach for overeoming fuel-element instability is to alloy the uranium to a greater extent to give the eubie isotropic $\gamma$-phase at fuel temperatures. Basic information pertaining to the processes oceurring when fuel elements are cooled has been obtained at the Institute by querching varions alloys at different cooling-rates to give a sequence of transformation struetures between $\gamma$ and $\alpha$. The physical properties, kinetics and mechanism of transformation of these alloys have been studied.

Zirconium and its alloys are important as canning and constructional materials in water-moderater reactors. The recent announcement by the United Kingdom Atomic Energy Authority of the projected development of the steam generating heavy water reactor makes the Institute's work on zirconium of particular interest. The reactive nature of zirconium has necessitated the design of a high-vacuum, hightempcrature X-ray camera for structural studies at temperatures up to $1,000^{\circ} \mathrm{C}$. The embrittling 'omega' phase has been studied in a number of binary zireonium systems and the nature of the omega phase and its derivation from the high-tomperature body-centred cubic structure of zirconium have been determined.

Beryllium has important applications as a nuclear and structural material by virtue of its low neutronabsorption cross-section and high strength/weight ratio; but its present use is limited by its inherent brittleness. The deformation characteristics of beryllium have been studied at Fulmer, and the present work is concerned with the effect of minute amounts of impurities in beryllium. It is thought, that some impurities form precipitation-hardening systems with beryllium and the mechanism of precipitation in beryllium having an artificially high iron content is being studied by X-ray diffraction. A specially designed $\mathrm{X}$-ray diffraction camera for studying the structure of liquid metals was demonstrated. Recent work has shown that the structure of liquid tin can be regarded as consisting of tetrahodra of grey tin in a random matrix. Work on alloy systems has shown that liquids of certain alloys, for example, gold-tin, copper-tin and gold-gallium, exhibit a high degree of order, and $\mathrm{X}$-ray diffraction work on these systems is being supplernented by density studies.

Chromium is attracting considerable interest as a high-ternperature material, but suffers from brittleness at room temperature. This brittleness is thought to be associated with the presence of impurities and tho Institute's fluoride process for electrodepositing purity chromium (10 p.p.m. nitrogen, 200 p.p.m. oxygen and 80 p.p.m. hydrogen) is an important contribution in this sphere. Exhibits included a 4-in. diameter chromium ingot prepared at Fulmer by melting electro-doposited flakes in a consumable ure furnace, and extruded chromium bars. 